Flamsteed was intrigued, and near the end of his life he remarked to Sharp: "You see that neither Age nor Infirmitys, nor any discoragements hinder me from seeking after knowledg and Truth."

Particularly revealing were the nowforgotten amateur astronomers who wrote detailed letters comparing their observations with a variety of competing astronomical tables. Clearly the "great inequality" of Jupiter and Saturn was raising its head, not to be solved till the end of the eighteenth century. In the final paragraph Flamsteed wrote to Sharp, a month before his death, he remarked: "but Saturn and Jupiter will find worke for those that come after us."

Owen Gingerich is at the Harvard-Smithsonian Center for Astrophysics, Cambridge,

Massachusetts 02138, USA.

\section{Evolution by design?}

\section{No Free Lunch: Why Specified Complexity Cannot Be Purchased without Intelligence by William A. Dembski}

Rowman \& Littlefield: 2002. 432 pp. \$35, £27

\section{Brian Charlesworth}

Newton believed that his discoveries revealed the Universe to be subject to the "counsel and dominion of an intelligent and powerful Being". A century later, Laplace famously remarked that "I had no need of that hypothesis", after completing his revision of celestial mechanics. The whole enterprise of modern science is built on the assumption that nature can be understood without appealing to the intervention of gods or goblins. Most people would agree that it has been remarkably successful.

William Dembski and his fellow advocates of "Intelligent Design" want to turn the clock back. They claim that darwinian evolution is inadequate to explain the intricate adaptations that can be seen in even the simplest single-celled organism. Their position differs from that of the biblical creationists in that they accept the scientific estimates of the age of the Earth and the Universe, and even allow a limited role for evolutionary processes such as natural selection. Their arguments are dressed up with a good deal of philosophical and mathematical formalism, but conclude with an appeal to the continual intervention of an unobservable designing intelligence in the course of nature. This smacks of the Middle Ages.

Dembski uses two arguments, neither of which is new. The first is based on the problem of "specified complexity": the improbability of assembling a functioning complex

system by randomly combining numerous individual components. This is a variant of Hoyle and Wickramasinghe's old claim that the probability of assembling a functioning protein out of a random set of amino acids is similar to that of Concorde being constructed by a tornado hitting a junkyard. As Darwin made abundantly clear, this is not the way that evolution by natural selection is thought to work. Rather, a step-by-step adjustment of individual characters occurs, each of which is advantageous in terms of darwinian fitness.

After a good deal of twisting and turning, Dembski concedes that this model of adaptive evolution can indeed work, and produce the appearance of design. But he then argues that there is still no "free lunch", since we have to be able to explain the trajectory over time of the relationships between character states and fitness. According to him, this requires the intervention of an intelligent designer, rather than the interaction of an evolving population with a changing physical and biotic environment. This ignores the large body of biological evidence on the emergence of evolutionary novelties in response to new environments, seen on a small scale in island radiations such as Darwin's finches, and on a large scale in such events as the evolution of mammalian groups after the extinction of the dinosaurs.

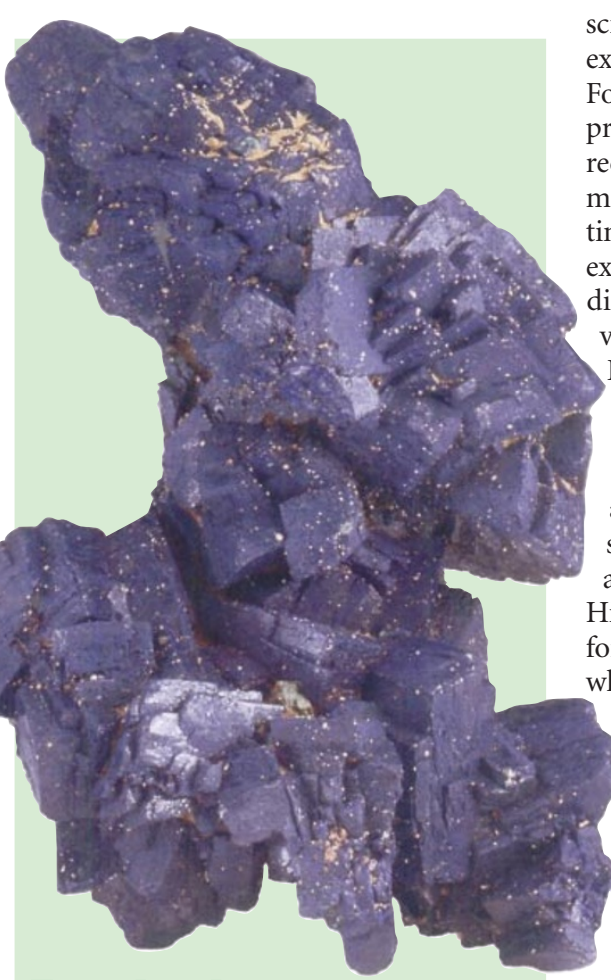

\section{Rocky blues}

Azurite, found in Chessy, France. Taken from Photographic Guide to Minerals of the World by Ole Johnsen (Oxford University Press,

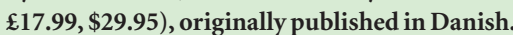

The second argument is that of "irreducible complexity" - that a piece of biological machinery made up of many integrated components, such as a bacterial flagellum, may fail to work if even one of them is removed. This is taken to imply that it could not have evolved via a series of functional intermediates. Again, this argument was considered by Darwin in his famous discussion of the eye. Darwin pointed out that, although we have no evidence about the actual historical course of events that led to the evolution of the vertebrate eye, we do have many different types of eyes represented among living animals, ranging from simple light-sensitive cells to the elaborate camera-like eyes of cephalopods and vertebrates. A series of gradual steps leading from the simplest up to the most elaborate eye can be reconstructed, each of which involves a light receptor that is of use to its possessor.

Like other historical sciences, evolutionary biology attempts to interpret the past in the light of processes that can be observed to be acting today. The direct record of what actually happened, as revealed in the fossil record, is necessarily incomplete, especially with respect to very remote events such as the origin of life itself. Nevertheless, we can ask if what we see in the living world, both in the past and today, is consistent with what is expected from our models of evolution. The scientific literature on evolution is full of examples of people trying to do just that. For example, if a lack of intermediates is a product of the incompleteness of the fossil record, we would expect to see more and more discoveries of intermediate forms as time goes by. Human evolution provides an excellent example of this, with the fossil discoveries of the twentieth century providing a resounding confirmation of Darwin's hypothesis of an African origin of modern humans.

In contrast, Dembski prefers to fill up the gaps in our knowledge by invoking an agent whose acts have no observable consequences. He smugly refuses to provide any details of what the designer has in mind. His theory can explain anything, and therefore explains nothing. If one tries to imagine what the designer is like by looking at the

facts of biology, one is likely to come to rather uncomfortable conclusions. As J. B. S. Haldane wrote in 1932: "Blake expressed some doubt as to whether God had made the tiger. But the tiger is in many ways an admirable animal. We have now to ask if God made the tapeworm. And it is questionable whether an affirmative answer fits in either with what we know about the process of evolution or what many of us believe about the moral perfection of God."

Brian Charlesworth is at the Institute for Cell,

Animal and Population Biology, University of Edinburgh, Edinburgh EH93JT, UK. 